Courrier du Centre international Blaise Pascal

12 | 1990

Varia

\title{
La vie de l'Association
}

\section{Thérèse Goyet}

\section{OpenEdition}

Journals

Édition électronique

URL : http://journals.openedition.org/ccibp/640

DOI : $10.4000 /$ ccibp. 640

ISSN : 2493-7460

\section{Éditeur}

Centre international Blaise Pascal

\section{Édition imprimée}

Date de publication : 4 janvier 1990

Pagination : 29

ISSN : 0249-6674

\section{Référence électronique}

Thérèse Goyet, «La vie de l'Association », Courrier du Centre international Blaise Pascal [En ligne], 12 | 1990, mis en ligne le 08 janvier 2016, consulté le 14 septembre 2020. URL : http:// journals.openedition.org/ccibp/640

Ce document a été généré automatiquement le 14 septembre 2020.

Centre international Blaise Pascal 


\section{La vie de l'Association}

\section{Thérèse Goyet}

1 Pour l'année 1989, l'association Amis et Correspondants du CIBP a tenu à la Faculté des Lettres, 29 Boulevard Gergovia, Salle des Actes, le même jour, vendredi 15 décembre 1989, deux assemblées générales à la suite l'une de l'autre. 98 membres étaient présents ou représentés.

2 La première, "assemblée extraordinaire ", a procédé à la modification de l'article 10 des statuts de 1980 .

3 L'objectif était de simplifier les modalités d'élection du Conseil, le fractionnement par tiers annuel étant peu pratique, de susciter de plus nombreuses candidatures, et d'assurer la solidité du Bureau sous la responsabilité du Conseil.

4 La rédaction adoptée à l'unanimité est la suivante : «Les membres du Conseil élus par l'Assemblée générale le sont pour trois ans; ils sont rééligibles. Leur nombre sera de cinq au moins, sans limitation supérieure.

5 En cas de vacance dans le Bureau, le Conseil choisit parmi ses membres un remplaçant qui reste en charge jusqu'au renouvellement ordinaire du Conseil. »

6 L'assemblée générale ordinaire s'est déroulée selon l'ordre du jour suivant :

7 1) Lecture du rapport moral, compte-rendu de l'assemblée générale de 1988, par la secrétaire, $\mathrm{M}^{\text {Ile }}$ Sart. Approbation à l'unanimité.

8 2) Rapport financier par M. Descotes trésorier. Approbation à l'unanimité.

9 3) Bilan de l'année.

10 L'association compte neuf ans d'âge ; qu'on mesure le progrès accompli en comparant les numéros 1 et 2 du Courrier du CIBP, simple appel prospectif et définition administrative, à l'important n 10 (millésimé 1988).

11 M. Descotes, Directeur scientifique du Centre International Blaise Pascal, retrace les actions de notre association de soutien.

Il indique le nombre d'adhérents (188). 

(1984-1985).

14 4) Activités prévues pour 1990 : la plus importante sera, avec la participation des Amis de Port-Royal, le colloque « Droit et pensée politique autour de Pascal » qui se tiendra à la Faculté des Lettres du 20 au 23 septembre. L'Université nous aide notamment en hébergeant les congressistes dans une résidence d'étudiants, et la Ville s'ouvre aux participants : visite touristique, réception à l'Hôtel de Ville, excursion extra-muros. Nous aurons une manifestation à Notre-Dame du Port, une exposition dans une salle municipale.

$\mathrm{M}^{\mathrm{e}}$ Sérandon, représentant de la Municipalité, expose les possibilités d'ouverture. Le souvenir de Pascal est devenu une composante vigoureuse de notre vie sociale.

5) La rubrique des dons faits au CIBP reprendra dans le Courrier $n^{\circ} 11$.

6) Le chiffre de la cotisation pour 1990 est fixé à $80 \mathrm{~F}$ pour les membres actifs, à $250 \mathrm{~F}$ pour les bienfaiteurs.

18 L'ordre du jour étant épuisé, la présidente invite tous les membres présents à passer dans une autre salle pour regarder le film sur le congrès tenu au Japon.

\section{AUTEUR}

\section{THÉRÈSE GOYET}

Directeur adjoint du CIBP 